Volume 9, No.4, July - August 2020

International Journal of Advanced Trends in Computer Science and Engineering

Available Online at http://www.warse.org/IJATCSE/static/pdf/file/ijatcse332942020.pdf

https://doi.org/10.30534/ijatcse/2020/332942020

\title{
MISTMATIC: Automatic Misting Control System for Indoor Garden with Rule-Based Approach
}

\author{
Mon Arjay F. Malbog ${ }^{1}$, Julius C. Castro ${ }^{2}$, Christopher Franco Cunanan ${ }^{3}$, Nelson M. Pateña ${ }^{4}$, \\ Bobby M. Bastes 5 \\ ${ }^{1}$ Technological Institute of the Philippines, Manila Philippines, malbog.monarjay@gmail.com \\ ${ }^{2}$ Bohol Island State University, Tagbilaran Bohol Philippines, julcas_cvscaft@ yahoo.com.ph \\ ${ }^{3}$ Polytechnic University of the Philippines, Santa Maria Bulacan, Philippines, christophercunanan @ yahoo.com \\ ${ }^{4}$ Bohol Island State University, Tagbilaran Bohol Philippines, nels_pat59@bisu.edu.ph \\ ${ }^{5}$ Bohol Island State University, Tagbilaran Bohol Philippines, bobskhee@gmail.com
}

\begin{abstract}
Today, indoor gardening provides a stable food supply in end consumers, restaurants, and retailers. Extreme heat affects stress to the plants that can lead to exhaustion. Research says that plants are said to be on optimal condition if the temperature only ranges between 15-34 degrees Celsius. Anything higher than the said temperature will cause plants to suffer, deteriorate, and also affect the plants' productivity. The researchers successfully developed an automatic mist machine that is capable of cooling a surrounding area that can control the rise of temperature in protecting and maintaining the optimal temperature required for indoor plants in a garden with a Rule-Based method. The results of the two trials were all the same when it comes to temperature and humidity over time. The rise of temperature was the decrease in humidity and vice versa, making it inversely proportional to each other. However, it resulted that the higher the height of placement of the prototype, the longer it takes to cool down the surrounding area. The study shows that the testing of functionality and validation of the system resulted in a $100 \%$ success rate. The study verifies and proves that the system is effective and efficient in the issue of the temperature control system.
\end{abstract}

Key words : Arduino, Indoor Garden, Misting, Rule-Based, and Temperature Control,

\section{INTRODUCTION}

The Philippines is devastated and ruin by up to 10 tropical storms in a year and storms can destroy crops and interrupt food supply. So, Indoor farming is used to grow the plant inside the house and protect the crop from a natural disaster [1]. Today, indoor farming provides a stable food supply in end consumers, restaurants, and retailers. The application of modern ideas for indoor farming uses Controlled Environment Agriculture (CEA) technology where the technology controls the temperature, humidity, soil moisture [2], [3], and light that makes the production of crops indoor possible. Gathered temperature can directly control the productivity of the plants [4]. Too high and too low-temperature supply to the plant can spoil the biochemical process and can cause an end to the plant growth.

The temperature can limit the growth of the plant and probably within the corresponding wide-ranging temperature restrictions [5]. The growth of the plant has three basic temperature points: first is the minimal temperature, the meaning is adequate for the plant growth to begin; second is the optimal temperature, the most beneficial for the plant growth; and the maximum temperature, at this point the plant growth ends. But some plant growth varies depending on the development stage, temperature adaptation, time of day, and the season.

Nowadays, due to global warming, the increase in temperature is causing a huge problem the world faces every day. The average global temperature has increased by about 1.4 degrees Fahrenheit (0.8 degrees Celsius) over the past 100 years, according to the National Oceanic and Atmospheric Administration (NOAA). This leads to experiencing extreme heat that can have a major effect on living organisms all over the world.

Extreme heat affects stress to the plants that can lead them to exhaustion. Research says that plants are said to be on optimal condition if the temperature only ranges between 15-34 degrees Celsius. Anything higher than the said temperature will cause plants to suffer and deteriorate. The extreme temperature will also affect the plants' productivity. So, watering the plant is important in gardening for controlling the amount of water and temperature [6]. In irrigation, an automatic watering system was used for their plants [7] but sometimes the amount of water going to the plants is too much.

The goal of the study is to develop an automatic misting system that controls the temperature of the surrounding of the indoor garden. Specifically, this study aims to assess the 
effectiveness of the automatic mist machine involving cooling in terms of the time it will take for the temperature in the surrounding area to reach the optimal temperature required which is 34 degrees Celsius and to determine the lowest possible temperature achieved by the product in cooling the surrounding area. The study will benefit the garden owner because it will automatically water the plant through the use of a water misting system.

Misting system is used for fire extinguishing systems [8], controlling dust in the industrial warehouse [9], [10], and watering in the garden to create moist and humid surroundings. Usually, apply in hot weather to keep it cool and for tropical plants. Misting is widely known in agriculture application and sometimes misting nozzle is called foggers.

Gardening is one of the most preferable hobbies for most of people. There is one study prove an effective way of gardening through the use of "Smart Gardening", which converts all manual labor to an automatic system for watering and giving light to the plants [11]. The system also has an intruder detection camera to detect the intruders. Another smart watering system used in gardening with measuring the soil content and control the rate of flow of water to a sprinkler [12]. The system was controlled by a microcontroller Arduino and the goal of the study is to save water in gardening.

There is one study that was able to develop a system that can do the watering, fog the environment, and at the same time drain hydroponic nutrients automatically the garden [13]. Using the Internet of Things (IoT) and hydroponics to grow plants without soil is an example study that can be used in indoor gardening. The system was controlled by microcontrollers and sensors to keep the intervention of the owner of the garden at a minimum [14].

\section{METHODOLOGY}

\subsection{System Architecture}

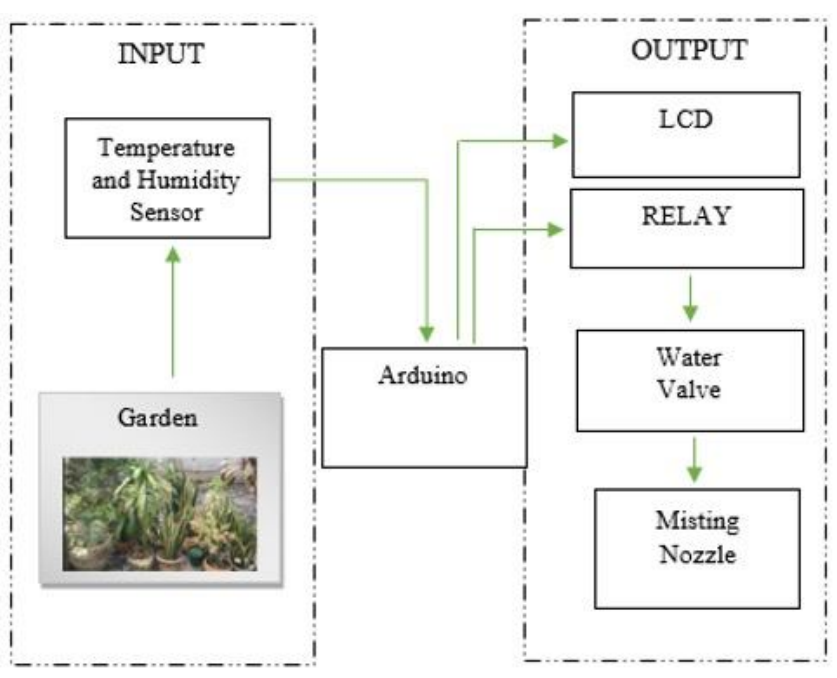

Figure 1: MISMATIC System Architecture
Figure 1 shows the connection of the devices and form as Automatic Mist System that is a temperature-dependent cooling device that can cool its surrounding area by using Arduino Uno. The Arduino Uno was programmed with rules of codes called Rule-Based, which will control the input and output devices. Misting produces mist rather than cool air. Temperature and Humidity Sensor (DHT11) are used as an input device to detect the garden surrounding readings. The study includes Water Solenoid Valve, Water Pipe, Piping Accessories, and 16x2 LCD as output devices. LCD device shows the values being read by the temperature sensor. All the materials have been used to make the Automatic Mist Machine.

\subsection{Flowchart of the System}

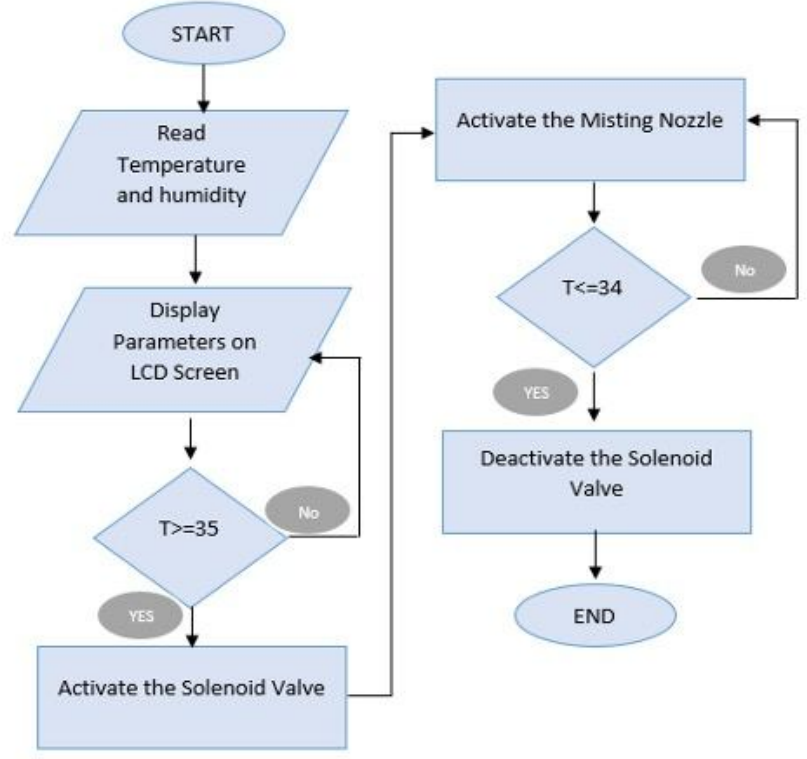

Figure 2: MISMATIC Flowchart

The system was designed with a supply 12 volts DC to the solenoid valve, 5 volts DC to Arduino, and plugged-in the water hose on the lower right side of the prototype. Figure 2 shows the flowchart of the automatic misting machine and begins by reading the temperature and humidity of the plants' surrounding using the DHT11 sensor. The LCD will then display the values of these two parameters read by the sensor. Once the temperature value reaches the threshold, which is any number greater than or equal to 35 degrees, it will stimulate the solenoid valve to open. Simultaneously, the misting nozzle will also be stimulated and will begin the misting of the surroundings. Due to this mist, the atmosphere will be regulated, and the appropriate temperature for the plants will be provided. If the temperature then decreased to any number less than or equal to 34 degrees, the system will close the valve, dismissing the flow of the water to the nozzles which will disable the misting. The process continues until the ideal temperature of the household plants' surroundings is regulated. 


\subsection{Schematic Diagram of the System}

Figure 3 shows the connection of the whole system devices to the microcontroller. At pin A4 and A5 of the Arduino Uno, the LCD $12 \times 2$ is connected which shows the output reading of the DHT11 Temperature and Humidity sensor which on the other hand is connected at pin 7. Moreover, the $12 \mathrm{~V}$ Electric Water Solenoid Valve is seen at digital pin 10 of the Arduino through a relay circuit. The water solenoid is a normally closed valve which means that whenever 12 volts are being fed to it, the valve will open. The water source is connected to the inlet of the valve where it allows water to flow. Furthermore, 2 misting nozzles are connected to the outlet of the valve which is placed and assembled along PVC pipes.

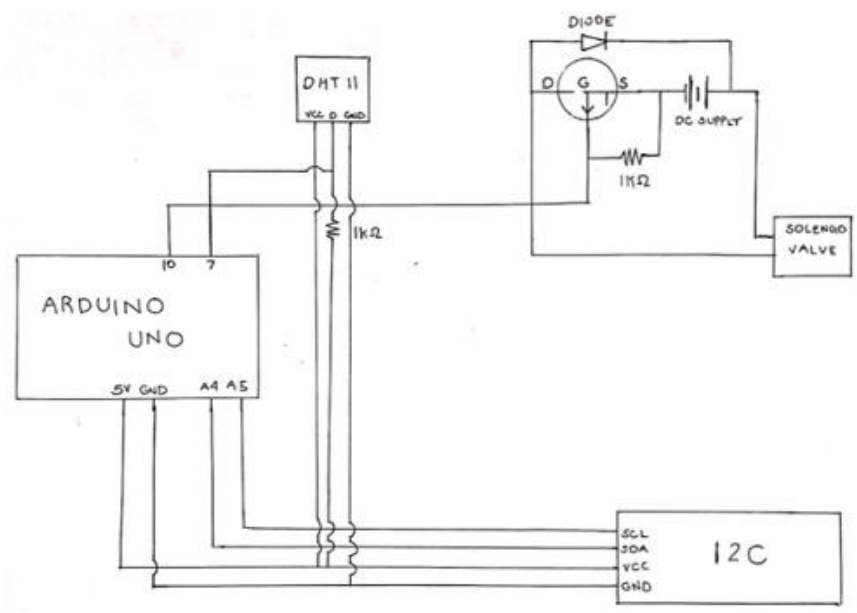

Figure 3: MISMATIC Schematic Diagram

\subsection{Materials and Components}

To develop the MISTMATIC: Automatic Misting System through Controlled Temperature Measurement with Rule-Based Approach, the following materials were applied to the proposed system:

\section{A. Arduino UNO}

Arduino Uno was a microcontroller where the program was stored and the brain of the whole system [15]. Arduino controlled the input and output devices as well as the processing condition of the program [16], [17].

\section{B. Liquid Crystal Display (LCD)}

Liquid Crystal Display (LCD) is the device used to output the readings of the sensor [18].

\section{Relay and Water Solenoid}

Arduino Relay and Water Solenoid valves are used for simple on/off control of the water flow.

\section{Misting Nozzle}

Misting Nozzle used to spray mist for a cooling system of the indoor garden. This component will produce mist to change the temperature of the environment and water the plants.

\subsection{Rule-Based}

The Rule-Base is storage of rules and each rule is designed by the "IF-THEN" statement [19]. A knowledge illustration type used in Artificial Intelligence called a rule base. The IF part is the conditional specified information and the THEN part is the action of the system. To respond to a problem, a rule offers some descriptions and the following rule that are used in the system:

1) if (Readings are detected) then (Display the readings to the $L C D$ )

2) if (temperature is greater than or equal $35^{\circ} \mathrm{C}$ ) and (humidity is HIGH) then (Activate the solenoid valve) 3) if (temperature is less than or equal $34^{\circ} \mathrm{C}$ ) and (humidity is NORMAL) then (Deactivate the solenoid valve)

\subsection{Hardware Prototype of the MISMATIC}

Figure 4 shows the prototype of the Automatic Misting System. The two brass that can be seen in the photo is the misting nozzles that provide fine drops of water. It is where the cooling of the surrounding process takes place. The plants present in this application were Snake plant, Fern, Fortune plant, Aloe Vera, Palm plant, and Spider plant. Their productivity was based on temperature and moisture of the soil which was monitored using the DHT11 sensor which was placed at the side of the first nozzle to the right, connected into circuitry and Arduino Uno. Any value of temperature higher than 34 degrees can have bad effects or worse dry the plants. The location of the DHT11 sensor is in between the two misting nozzles.

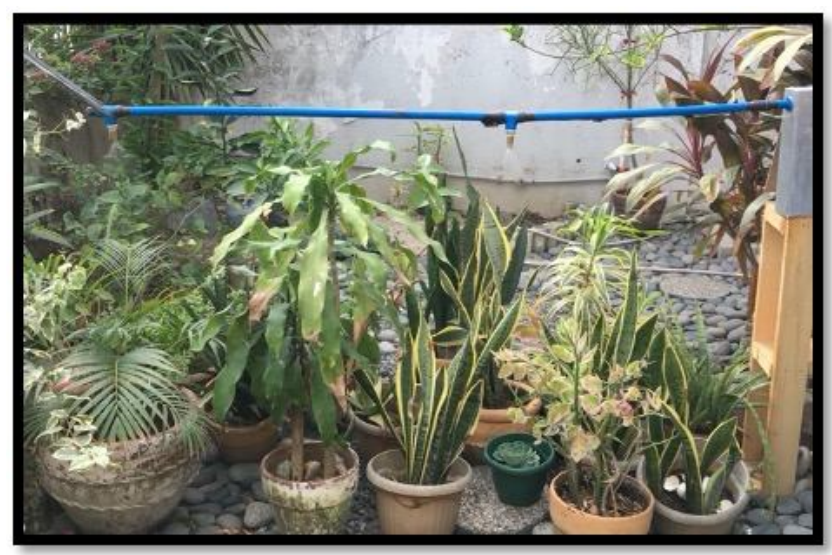

Figure 4: Indoor Garden and the Prototype

Figure 5 shows the components placing inside the prototype and the following are the labels in the image: 1) Arduino Uno; 2) Cable Connector; 3) LCD Screen; 4) PCB Circuit; 5) Metal Coupling; 6) Solid Wires; 7) 12volts Solenoid Valve; 8) PCV Pipes; 9) Hose Connector; 10) Direct Hose, and 11) Plywood Casing. 


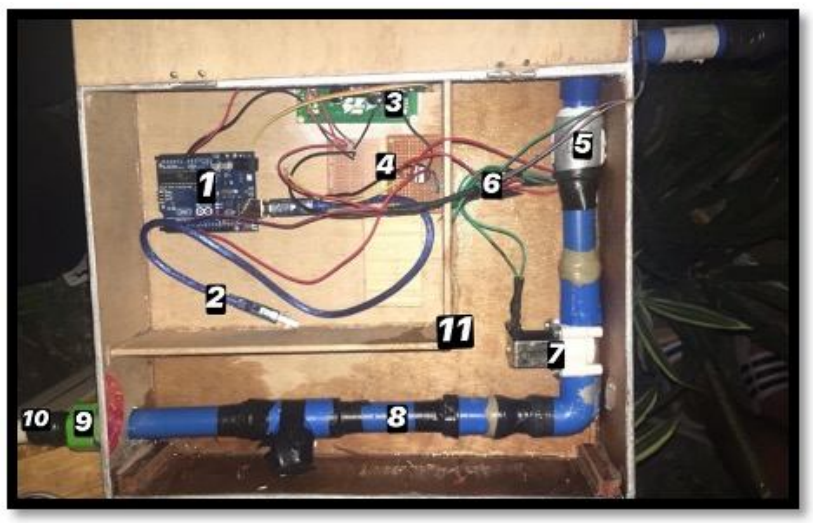

Figure 5: Inside Part of the Prototype

\section{RESUlt AND DiscusSion}

\subsection{Functionality Testing}

Functionality testing for the Automatic Misting System was done by the researchers to check if the hardware components and software performs as expected. Table 1 shows the software and hardware components testing.

Table 1: Testing of the components

\begin{tabular}{|l|l|}
\hline No. & \multicolumn{1}{c|}{ Testing Activities } \\
\hline 1 & The sensor will measure the temperature and humidity level. \\
\hline 2 & The LCD will output the readings of the sensor \\
\hline 3 & The Misting Nozzle will be activated and produce mist \\
\hline 4 & The Misting Nozzle will be deactivated \\
\hline
\end{tabular}

\subsection{System Setup}

\section{$\mathrm{L}$}

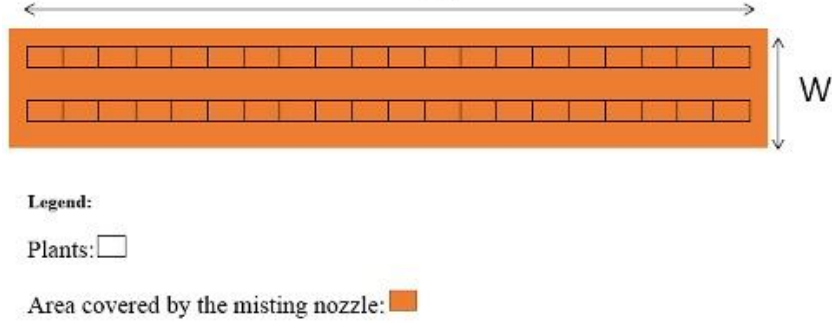

Figure 6: Wide Range Area of the Misting Nozzle

The researchers compute first the misting nozzle range in the garden. Equation 1 shows the computational formula to accumulate the area range of the two-misting nozzle. The researchers set two (2) trials with different height of nozzle. Figure 6 shows the area computation of the garden range of the misting nozzle.

\section{Area $=$ Length $\mathrm{x}$ Width}

TRIAL 1: Height of misting nozzle $=1 \mathrm{~m}$

AREA $=2.1336 \mathrm{~m} \times 1.2192 \mathrm{~m}$

AREA $=2.6013$ sq. meters
TRIAL 2: Height of misting nozzle $=1.143 \mathrm{~m}$

AREA $=2.5908 \mathrm{~m} \times 1.3716 \mathrm{~m}$

AREA $=3.5535$ sq. meters

The computations consist of the height, length, width, and the total area that can be covered by the misting. In trial 1 , the researchers placed the device with a height of $1 \mathrm{~m}$ having $2.6013 \mathrm{~m}^{2}$ area covered. In trial 2, with a height of $1.143 \mathrm{~m}$, the area covered was $3.5535 \mathrm{~m}^{2}$; which proves that the higher the height where you placed the misting device, the larger area it covers.

\subsection{Testing and Result}

Testing is done with two (2) trials and Table 2 shows the result of the first trial. When the device was turned on, initially the temperature and humidity reading was $33{ }^{\circ} \mathrm{C}$ and $58 \%$ respectively.

Table 2: Results of Trial 1

\begin{tabular}{|c|c|c|}
\hline Time(seconds) & Temperature $\left({ }^{\circ} \mathrm{C}\right)$ & Humidity (\%) \\
\hline 0 & 33 & 58 \\
\hline 1 & 33 & 58 \\
\hline 2 & 33 & 58 \\
\hline 4 & 33 & 58 \\
\hline 6 & 33 & 58 \\
\hline 8 & 34 & 58 \\
\hline 10 & 34 & 57 \\
\hline 12 & 34 & 57 \\
\hline 14 & 35 & 57 \\
\hline 16 & 35 & 57 \\
\hline 18 & 35 & 50 \\
\hline 20 & 36 & 50 \\
\hline 22 & 37 & 50 \\
\hline 24 & 37 & 50 \\
\hline 26 & 37 & 50 \\
\hline 36 & 37 & 49 \\
\hline 48 & 36 & 49 \\
\hline 52 & 36 & 48 \\
\hline 64 & 35 & 48 \\
\hline 78 & 35 & 49 \\
\hline 80 & 34 & 50 \\
\hline 82 & 33 & 54 \\
\hline 83 & 33 & 58 \\
\hline
\end{tabular}

Slowly the temperature increases and at 10 seconds, the temperature and humidity reading were $34 \mathrm{C}$ and $57 \%$. As the temperature continuously increases, at 14 seconds, you can see that the readings were $35{ }^{\circ} \mathrm{C}$ and $57 \%$ humidity, which was the starting point that it will trigger and start misting (solenoid valve is now open). At 36 seconds having the maximum temperature reading $37{ }^{\circ} \mathrm{C}$ and $49 \%$ humidity. As the misting continues and is still on, the temperature slowly decreases and the humidity finally increases. At 80 seconds, the reading was $34{ }^{\circ} \mathrm{C}$ temperature and $50 \%$ humidity, which will be the time when the circuitry will be disabled and the solenoid valve. In this trial, testing able to have the lowest temperature result of $33{ }^{\circ} \mathrm{C}$ and $58 \%$ as the highest value of humidity, where values returned to the initial reading by the DHT11 sensor. 
Table 3: Results of Trial 2

\begin{tabular}{|c|c|c|}
\hline Time(second) & Temperature $\left({ }^{\circ} \mathrm{C}\right)$ & Humidity $(\%)$ \\
\hline 0 & 33 & 56 \\
\hline 2 & 33 & 56 \\
\hline 4 & 33 & 56 \\
\hline 10 & 33 & 56 \\
\hline 12 & 34 & 57 \\
\hline 14 & 34 & 57 \\
\hline 30 & 34 & 56 \\
\hline 36 & 34 & 55 \\
\hline 44 & 34 & 54 \\
\hline 64 & 34 & 54 \\
\hline 74 & 35 & 51 \\
\hline 84 & 35 & 50 \\
\hline 94 & 35 & 50 \\
\hline 120 & 35 & 50 \\
\hline 152 & 36 & 51 \\
\hline 158 & 36 & 51 \\
\hline 162 & 35 & 53 \\
\hline 170 & 34 & 53 \\
\hline 176 & 33 & 53 \\
\hline 180 & 33 & 53 \\
\hline
\end{tabular}

Table 3 shows the results of the second trial. Initially, the temperature and humidity readings were $33{ }^{\circ} \mathrm{C}$ and $56 \%$ respectively at 0 seconds. The temperature increases at 12 seconds, the readings were $34{ }^{\circ} \mathrm{C}$ temperature and $57 \%$ humidity. As the temperature again continuously increases at 74 seconds, the readings were $35^{\circ} \mathrm{C}$ temperature and $51 \%$ humidity, again reaching the threshold will trigger and start misting (solenoid valve is now open). At 58 seconds the system getting the maximum temperature reading at this trial having $36^{\circ} \mathrm{C}$ and $51 \%$ humidity. As the misting continues and is still on, the temperature slowly decreases and the humidity again increases. At 170 seconds, the reading was $34^{\circ} \mathrm{C}$ temperature and $53 \%$ humidity, which will be the time when the circuitry will be disabled and the solenoid valve will be closed. In the second trial, the researchers were able to have the lowest temperature result of $33^{\circ} \mathrm{C}$ and $53 \%$ as the highest value of humidity.

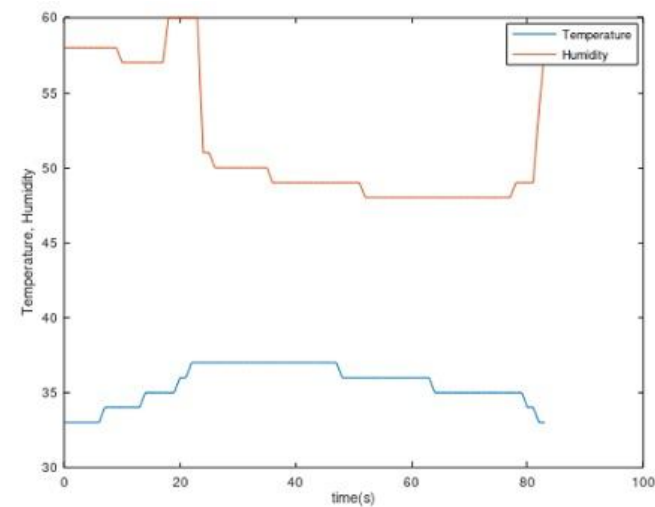

Figure 7: Trial 1 Graph of Temperature and Humidity over Time

In figure 7 shows the graph with plotted values of the data gathered in Table 2. The graph still shows that the rise of the temperature is the decrease in the values in humidity. The highest temperature was attained from 22 seconds to 47 seconds is $37^{\circ} \mathrm{C}$. The lowest humidity was at $48 \%$ for 50 seconds to 78 seconds.

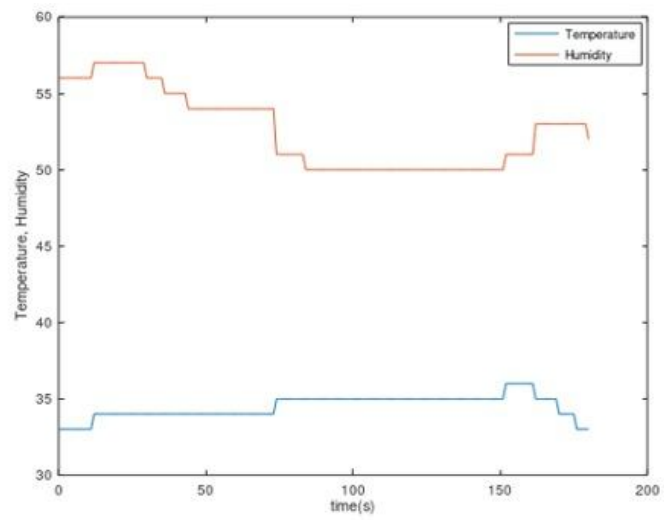

Figure 8: Trial 2 Graph of Temperature and Humidity over Time

In figure 8 shows the graph with the plotted values of the data gathered in Table 3 . The graph again proves that the increase of the temperature is the decrease in humidity. In this graph, the highest temperature was attained from 152 seconds to 158 seconds is $36^{\circ} \mathrm{C}$ and the lowest humidity was at $50 \%$ from 84 seconds to 120 seconds.

\section{CONCLUSION}

The researchers successfully developed an automatic mist machine that is capable of cooling a surrounding area that can control the rise of temperature in protecting and maintaining the optimal temperature required for indoor plants in a garden. The lowest temperature that the system can get resulted only to 33 degrees Celsius but perfectly fall on the range that the plants were said to grow fruitfully. Due to these results, the researchers conclude that as the height of placement increases, the area it covers become larger. The results of the two trials were all the same when it comes to temperature and humidity over time. The rise of temperature was the decrease in humidity and vice versa, making it inversely proportional to each other. However, it resulted that the higher the height of placement of the prototype, the longer it takes to cool down the surrounding area. The study shows that the testing of functionality and validation of the system resulted in a $100 \%$ success rate. The study verifies and proves that the system is effective and efficient in the issue of the temperature control system. The researchers would like to recommend to create a more stable stand and more suitable casing for the prototype. The researchers experienced difficulties in making a device perfectly without leak that is why we fully recommend future researchers to use Pipe cement and more Teflon tapes on the PVC pipes to avoid leakage. Adding a network sensor, monitoring through cloud or IoT, and deep learning approach is recommended by the study to make improvements to the system.

\section{ACKNOWLEDGEMENT}

The authors would like to express gratitude to the Technological Institute of the Philippines Manila Laboratory Facility for allowing them to use the equipment. 


\section{REFERENCES}

1. B. Min, and S. J. Park. A Smart Indoor Gardening System Using IoT Technology, Advances in Computer Science and Ubiquitous Computing, Springer, Singapore vol. $\quad 474, \quad$ pp. 683-685, 2018, doi.org/10.1007/978-981-10-7605-3_110.

https://doi.org/10.1007/978-981-10-7605-3_110

2. K.A. Olatunji, A. Oguntimilehin, and O. A. Adeyemo. A Mobile Phone Controllable Smart Irrigation System, International Journal of Advanced Trends in Computer Science and Engineering, vol. 9, no. 1, pp. 279-284, February 2020.

https://doi.org/10.30534/ijatcse/2020/42912020

3. M. A. F. Malbog, J. A. B. Susa, A. S. Alon, C. D. Casuat, and J. N. Mindoro. A Fuzzy Rule-Based Approach for Automatic Irrigation System through Controlled Soil Moisture Measurement, International Journal of Advanced Trends in Computer Science and Engineering, vol. 9, no. 2, pp. 2332-2337, April 2020. https://doi.org/10.30534/ijatcse/2020/216922020

4. A Sumarudin, A L Ghozali, A. Hasyim, and A Effendi. Implementation monitoring temperature, humidity and mositure soil based on wireless sensor network for e-agriculture technology, IOP Conference Series: Materials Science and Engineering, 2016, doi:10.1088/1757-899X/128/1/012044.

5. K. Sumathi, P. Adchaya, M. Jayasri, B,.Nandhini, and J. T. Pavithra. Smart Irrigation and Agriculture Monitoring system using Cloud Server based on IOT, International Journal of Advanced Trends in Computer Science and Engineering, vol. 9, no. 2, pp. 1082-1085, April 2020.

https://doi.org/10.30534/ijatcse/2020/28922020

6. D. Divani, P. Patil and S. K. Punjabi, Automated plant Watering system, 2016 International Conference on Computation of Power, Energy Information and Commuincation (ICCPEIC), Chennai, pp. 180-182, 2016, doi: 10.1109/ICCPEIC.2016.7557245.

7. M. Mayuree, P. Aishwarya and A. Bagubali. Automatic Plant Watering System, 2019 International Conference on Vision Towards Emerging Trends in Communication and Networking (ViTECoN), Vellore, India, pp. 1-3, 2019, doi: 10.1109/ViTECoN.2019.8899452.

8. S. Li, D. Yu, Z. Ling and W. Ding, The Application of Water Mist Fire Extinguishing System in Bus, 2019 9th International Conference on Fire Science and Fire Protection Engineering (ICFSFPE), Chengdu, China, pp. 1-5, 2019, doi: 10.1109/ICFSFPE48751.2019.9055783.

9. R. Soriano, Automated Misting System, Asia Pacific Journal of Multidisciplinary Research, Vol. 6, No. 4, pp. 94-100, November 2018.

10. Y. Ham et al., Spray Time Estimation of a High Pressure Water Supply System for Water Mist Spray, 2019 23rd International Conference on Mechatronics Technology (ICMT), SALERNO, Italy, pp. 1-4, 2019 doi: 10.1109/ICMECT.2019.8932137. https://doi.org/10.1109/ICMECT.2019.8932137

11. M. A. Muhtasim, S. Ramisa Fariha and A. M. Ornab, Smart Garden Automated and Real Time Plant
Watering and Lighting System with Security Features, 2018 International Conference on Computing, Power and Communication Technologies (GUCON), Greater Noida, Uttar Pradesh, India, pp. 676-679, 2018 doi: 10.1109/GUCON.2018.8675077.

12. K. N. Siva, R. Kumar G., A. Bagubali and K. V. Krishnan, Smart watering of plants, 2019 International Conference on Vision Towards Emerging Trends in Communication and Networking (ViTECoN), Vellore, India, pp. 1-4, 2019, doi: 10.1109/ViTECoN.2019.8899371.

13. M Mediawan, M Yusro, and J Bintoro, Automatic Watering System in Plant House - Using Arduino, $3 \mathrm{rd}$ Annual Applied Science and Engineering Conference (AASEC 2018), IOP Conference Series: Materials Science and Engineering, Bandung, Indonesia, pp. 1-7, April 2018, doi:10.1088/1757-899X/434/1/012220.

14. V. Palande, A. Zaheer, and K. George, Fully Automated Hydroponic System for Indoor Plant Growth, Procedia Computer Science, Vol. 129, pp. 482-488, 2018, doi:10.1016/j.procs.2018.03.028.

15. J. N. Mindoro, C. D. Casuat, A. S. Alon, M. A. F. Malbog, and J. A. B. Susa. Drowsy or Not? Early Drowsiness Detection utilizing Arduino Based on Electroencephalogram (EEG) Neuro-Signal, International Journal of Advanced Trends in Computer Science and Engineering, vol. 9, no. 2, pp. 2221-2226, April 2020. https://doi.org/10.30534/ijatcse/2020/200922020

16. C. D. Casuat, A. S. Alon, J. L. Dioses Jr., R. M. Dellosa, and R. A. Diamante, RFID Controlled "GG" Pieces Ranking Detection with Watch-Dog Enable, International Journal of Advanced Trends in Computer Science and Engineering (IJATSCE), vol. 9, no. 1.3, pp. 274-279, July 2020.

https://doi.org/10.30534/ijatcse/2020/4191.32020

17. J. A. B. Susa, M. A. F. Malbog, J. N. Mindoro, C. D. Casuat, and A. S. Alon. Automatic Room Humidifier and Dehumidifier Controller using Arduino Uno, International Journal of Advanced Trends in Computer Science and Engineering, vol. 9, no. 2, pp. 2208-2212, April 2020. https://doi.org/10.30534/ijatcse/2020/198922020

18. J. S. Gulmatico, A. S. Alon, M. A. F. Malbog, and R. I. Marasigan Jr., Tracking Utilizing Accelerometer and Piezoelectric Sensor, International Journal of Emerging Trends in Engineering Research (IJETER), India, vol. 8, no. 2, pp. 515-519, February 2020. https://doi.org/10.30534/ijeter/2020/39822020

19. A. S. Alon and J. A. B. Susa, Wireless Hand Gesture Recognition for an Automatic Fan Speed Control System: Rule-Based Approach, 2020 16th IEEE International Colloquium on Signal Processing \& Its Applications (CSPA), Langkawi, Malaysia, pp. 250-254, 2020. 